\title{
Chromium Effect as Grain Growth Inhibitor of Nanostructured WC-10Co after Sintering by Hot Isostatic Pressing
}

\author{
C. G. Garay-Reyes ${ }^{1}$, M. A. Ruiz-Esparza-Rodríguez ${ }^{1}$, I. Estrada Guel ${ }^{1}$, S. E. Hernández-Martínez ${ }^{2}$, J.L. \\ Hernández-Rivera $^{2}$, J.J. Cruz-Rivera ${ }^{2}$, J. S. Castro Carmona ${ }^{3}$ and R. Martínez-Sánchez ${ }^{1}$ \\ 1. Centro de Investigación en Materiales Avanzados (CIMAV), Laboratorio Nacional de \\ Nanotecnología., Chihuahua, Chih., México. \\ 2. Instituto de Metalurgia, Universidad Autónoma de San Luis Potosí, San Luis Potosí, S.L.P, México. \\ 3. Universidad Autónoma De Ciudad Juárez (UACJ)., Juárez, Chih., México.
}

Applications of nanostructured WC-Co cemented carbides include all areas where conventional materials are used. Recently has emerged a special interest in the synthesis of nanostructured WC-Co cemented carbides for the manufacture of cutting tools. In these applications, the nanostructured systems are preferred because the useful life of the tooling could be increased by a reduction in the grain size of the WC phase [1]. Conventionally, WC-Co cemented carbides are fabricated by mixing, compaction and sintering. The liquid-phase sintering process is carried out above the eutectic temperature of WCCo $\left(1280-1310{ }^{\circ} \mathrm{C}\right)$. In the case of cemented carbides the grain growth is favored by the high interfacial free energy. For this reason, the addition of grain growth inhibitors is necessary to control this growth during sintering either by modifying the WC-Co interface or by providing diffusion resistance [2]. Thus, the objective of the present work is to evaluate the effect of $\mathrm{Cr}$ as grain growth inhibitor on nanostructured WC-Co cemented carbides sintered by Hot Isostatic Pressing (HIP).

The starting materials consist of commercial WC (99.95\% pure), and elemental powders of Co and $\mathrm{Cr}$ (99.5\% pure). The nominal compositions of mixture were $\mathrm{WC}-10 \mathrm{Co}$ and $\mathrm{WC}-10 \mathrm{Co}$ (1Cr). Nanostructured powders were synthetized by milling process. The millings were performed by using a high energy mill Spex 8000. Milling conditions were set to $5 \mathrm{~h}$ of milling time, powder mass $8.5 \mathrm{~g}$ and a ball-to-powder ratio of 5:1. All milling run were performed with methanol as process control agent and argon as the inert milling atmosphere. The milled mixtures were consolidated by HIP, using $120 \mathrm{MPa}$ and two sintering temperatures, 1200 and $1350{ }^{\circ} \mathrm{C}$. The structural characterization and phases evolution of the milled mixtures was performed by X-ray diffraction analysis, in a Panalytical X'pertPRO diffractometer. Microstructure in sintered samples was evaluated in a SEM Hitachi SU3500. The Vickers hardness test was performed using LECO LM 300AT equipment. Estimations of the crystalline sizes in milled and sintered samples were calculated by the Scherrer equation. The density calculation on sintered samples was determined by the Archimedes method.

Fig. 1A shows the X-ray diffraction patterns of the WC-10Co sample sintered at $1200{ }^{\circ} \mathrm{C}$ (a) and WC$10 \mathrm{Co}(1 \mathrm{Cr})$ samples sintered at 1200 (b) and $1350{ }^{\circ} \mathrm{C}$ (c) by HIP. The values of density and Vickers microhardness $\mathrm{HV}_{0.30}$ obtained in WC-10Co sample sintered at $1200{ }^{\circ} \mathrm{C}$ and $\mathrm{WC}-10 \mathrm{Co}(1 \mathrm{Cr})$ samples sintered at $1200{ }^{\circ} \mathrm{C}$ and $1350{ }^{\circ} \mathrm{C}$ by HIP are show in Fig 1B. The microstructure of WC-10Co sample sintered at $1200{ }^{\circ} \mathrm{C}$ (Fig. 2 a-b) and WC-10Co (1Cr) samples sintered at 1200 (Fig. 2 c-d) and $1350{ }^{\circ} \mathrm{C}$ (Fig. 2 e-f) is composed of a light WC phase and a dark Co phase. It is concluded that crystallite size the WC-10Co and WC-10Co (1Cr) powders after sintering at $1200{ }^{\circ} \mathrm{C}$ show an increase of 121.7 and 24.7 $\%$ in its value, respectively, the WC-10Co (1Cr) powder after sintering at $1350{ }^{\circ} \mathrm{C}$ show an increase of $56 \%$ (crystallite size for WC-10Co and WC-10Co (1Cr)powders are 18.74 and $23.52 \mathrm{~nm}$, respectively). The microstructure of WC-10Co $(1 \mathrm{Cr})$ sample sintering at $1200{ }^{\circ} \mathrm{C}$ show a bimodal particle size 
distribution attributed to the Cr effect as particle growth inhibitor, which may be due to decrease in growth rate during re-precipitation. The higher values of density and Vickers microhardness $\mathrm{HV}_{0.30}$ are obtained in the WC-10Co $(1 \mathrm{Cr})$ sample after sintering at $1350{ }^{\circ} \mathrm{C}$, which is attributed to a high degree packing density and the effect of $\mathrm{Cr}$ as grain growth inhibitor.

References:

[1] H. Saito, A. Iwabuchi, T. Shimizu, Wear 261 (2006), p. 126.

[2] D. Sivaprahasam, S. B. Chandrasekar, R. Sundaresan, Int J Refract Met H 25 (2007), p. 14.
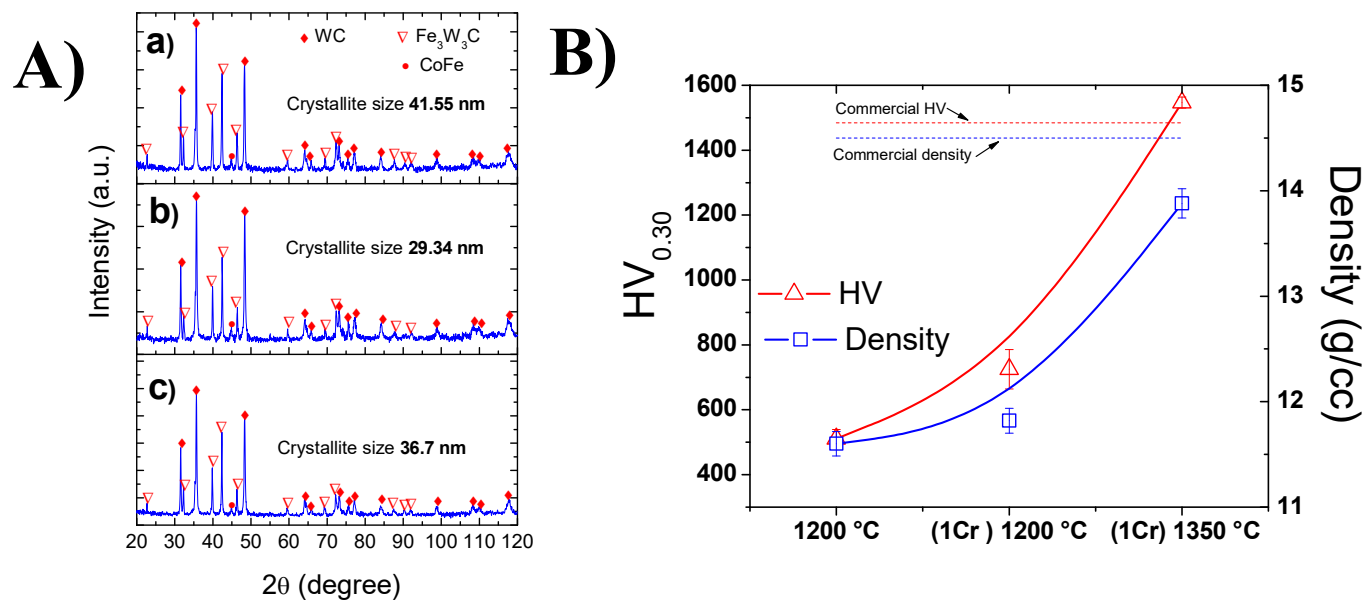

Figure 1. A) X-ray diffraction patterns and crystallite size obtained in WC-10Co sample sintered at $1200{ }^{\circ} \mathrm{C}$ (a) and WC-10Co (1Cr) samples sintered at 1200 (b) and $1350{ }^{\circ} \mathrm{C}$ (c) by HIP. B) Values of density and Vickers microhardness $\mathrm{HV}_{0.30}$ obtained in WC-10Co sample sintered at $1200{ }^{\circ} \mathrm{C}$ and $\mathrm{WC}$ $10 \mathrm{Co}(1 \mathrm{Cr})$ samples sintered at $1200^{\circ} \mathrm{C}$ and $1350{ }^{\circ} \mathrm{C}$ by HIP.
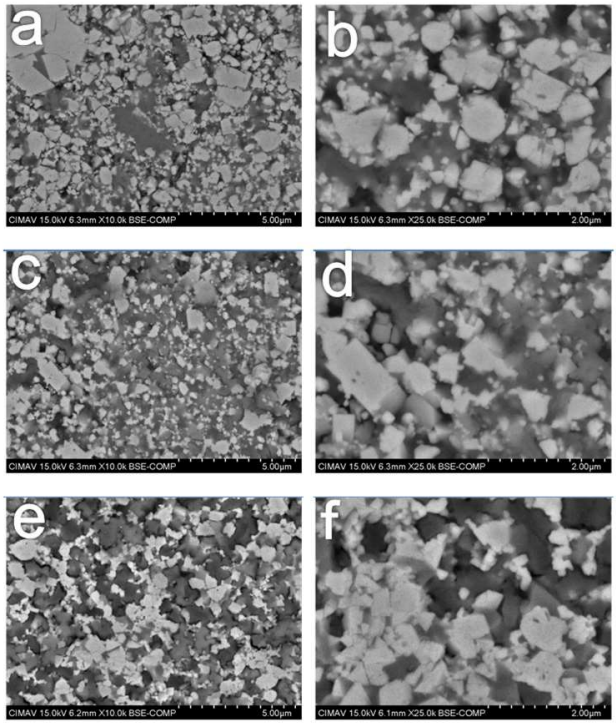

Figure 2. Micrographs obtained by SEM in WC-10Co sample sintered at $1200^{\circ} \mathrm{C}(\mathrm{a}-\mathrm{b})$ and $\mathrm{WC}-10 \mathrm{Co}$ (1Cr) samples sintered at $1200(\mathrm{c}-\mathrm{d})$ and $1350{ }^{\circ} \mathrm{C}$ (e-f) by hot isostatic pressing. 